\title{
Growth and Accumulation of Five Main Bioactive Components in the Roots of Salvia miltiorrhiza at Different Growth Stages and Using Different Culture Systems
}

\author{
Lilan Lu ${ }^{1}$, Shilong Fu ${ }^{1}$, Jian Feng ${ }^{1}$, Jianhe Wei ${ }^{1,2, ~ * ~}$ \\ ${ }^{1}$ Hainan Provincial Key Laboratory of Resources Conservation and Development of Southern Medicine, Hainan Branch of the Institute of \\ Medicinal Plant Development, Chinese Academy of Medical Sciences and Peking Union Medical College, Haikou, China \\ ${ }^{2}$ Key Laboratory of Bioactive Substances and Resources Utilization of Chinese Herbal Medicine, Ministry of Education \& National \\ Engineering Laboratory for Breeding of Endangered Medicinal Materials, Institute of Medicinal Plant Development, Chinese Academy of \\ Medical Sciences and Peking Union Medical College, Beijing, China
}

Email address:

wjianh@263.net (Jianhe Wei)

${ }^{*}$ Corresponding author

\section{To cite this article:}

Lilan Lu, Shilong Fu, Jian Feng, Jianhe Wei. Growth and Accumulation of Five Main Bioactive Components in the Roots of Salvia miltiorrhiza at Different Growth Stages and Using Different Culture Systems. Journal of Diseases and Medicinal Plants. Vol. 4, No. 3, 2018, pp. 59-68. doi: $10.11648 /$ j.jdmp.20180403.11

Received: April 23, 2018; Accepted: May 21, 2018; Published: June 8, 2018

\begin{abstract}
To Growth and accumulation of five main bioactive components in the roots of Salvia miltiorrhiza at different growth stages and using different culture systems. We analyzed growth parameters and the accumulation of selected bioactive components in Salvia miltiorrhiza that was grown in quartz sand-pot (hydroponic culture), soil-pot, and field culture systems at 3 growth stages (flower, root swelling, and mature). The highest bioactive compound concentrations (danshensu (DSS), 0.618 $\mathrm{mg} \cdot \mathrm{g}^{-1}$; salvianolic acid B (SAB), $52.5 \mathrm{mg} \cdot \mathrm{g}^{-1}$; cryptotanshinone (CTS), $0.617 \mathrm{mg} \cdot \mathrm{g}^{-1}$; tanshinone II A (TS II A), $1.11 \mathrm{mg} \cdot \mathrm{g}^{-1}$; and total tanshinone (TTS), $2.5 \mathrm{mg} \cdot \mathrm{g}^{-1}$, at the mature stage) were present in the roots of plants grown in the hydroponic culture system. These concentrations were significantly higher than those of plants grown in the field system. The highest values for root parameters ( longest root length (LRL), $46.72 \mathrm{~cm}$; largest root diameter (LRD), $14.68 \mathrm{~mm}$; and the number of roots per plant (RN), 9.56), plant biomass (shoot dry weight (SDW), $18.9 \mathrm{~g} \cdot$ plant $^{-1}$; root dry weight (RDW), $19.6 \mathrm{~g} \cdot$ plant $^{-1}$, at the mature stage), and yield (DSS, $8.36 \mathrm{mg} \cdot$ plant $^{-1}$; SAB, $657 \mathrm{mg} \cdot$ plant $^{-1}$; CTS, $7.95 \mathrm{mg} \cdot$ plant $^{-1}$; TS II A, $15.2 \mathrm{mg} \cdot$ plant $^{-1}$; and TTS, $30.7 \mathrm{mg} \cdot$ plant $^{-1}$, at the mature stage) were obtained from plants grown in the field system. Plants grown in the field culture system had significantly greater plant biomass and higher yields of bioactive compounds than plants grown in the quartz sand-pot (hydroponic culture) and soil-pot systems. Greenhouse hydroponic culture provides sufficient bioactive compound accumulation in the roots, but does not stimulate plant growth and root production. Therefore, the field system could greatly improve plant growth and root production in S. miltiorrhiza.
\end{abstract}

Keywords: Salvia miltiorrhiza, Culture System, Growth Stages, Bioactive Components, Growth

\section{Introduction}

Radix Salvia miltiorrhiza (Fam. Labiatae), Danshen, is an important medicinal plant that is widely used in traditional Chinese medicine for the treatment of chronic renal failure, bone loss, hepatitis [1-2], menstrual disorders, blood circulation diseases, coronary heart disease, and other cardiovascular diseases [3-6]. In recent years, Danshen has been introduced into Canada, Germany, America, the
Netherlands, South Africa, Russia, South Korea, and other countries and regions as a medicine for cardiovascular disease and to improve immunity [7].

The market demand for Danshen was initially satisfied by the collection of wild plants, but the increasing interest in herbal products has promoted the cultivation of $S$. miltiorrhiza [8]. Furthermore, there is considerable international interest in medicinal and aromatic plant culture [9-11]. This interest is largely due to the growing international interest in traditional 
herbal treatments, which has increased demand for natural raw medicinal materials by the pharmaceutical industry [12]. To meet this demand, controlled-environment production systems for medicinal plants have been developed in addition to traditional cultivation in outside fields.

Medicinal plant production is different from the production of other agricultural products in that medicinal plants are grown to produce specific phytochemicals for human use. Different medicinal plants are suited to different culture systems. The traditional outdoor field culture system is often considered to be the optimal culture method for most crops and medicinal plants because it provides the highest root yields and the best marketing attributes [13-14]. In recent decades, some medicinal plants have been produced using soil-less culture systems. Hydroponic production of medicinal and aromatic herbs is a new method for the mass production of these plants that results in high yields of high-quality secondary metabolites [15-19]. Numerous studies have shown that soil-less culture production of plants, particularly medicinal herbs, has many valuable advantages, including the following: high yields; faster crop growth; year-long cultivation when appropriate planting schedules and multiple harvest schemes are used; and high quality raw material that is clean and easy to process due to minimal contamination from herbicide and pesticide residues and microorganisms $[9,20]$. At present, different techniques can be used for hydroponic cultivation, including water culture, nutrient film techniques, aeroponics, and container culture in artificial substrates (i.e. quartz sand, vermiculite, or river sand matrix) [21-22]. Among these techniques, container culture in quartz sand requires a relatively low initial investment and has low running costs. This technique is generally used for short-cycle greenhouse cultivation of root vegetables that are marketed as fresh-cut products.

Previous studies suggest that controlled-environment soil-less, soil, and outside field culture systems could be profitably applied to the cultivation of medicinal plants [23]. all 3 systems can be used for plants with roots that are used medicinally and that the best system to use differs between plant species. To date, however, there have been studies that have directly compared these cultivation systems for the production of $S$. miltiorrhiza and its bioactive compounds.

In this study, $S$. miltiorrhiza seedlings were grown in quartz sand-pot, soil-pot, and outside field systems with an adequate supply of nutrients. The growth of plants and the accumulation of bioactive components at different growth stages in the 3 culture systems were evaluated in separate experiments that were conducted in 2015 and 2016.

Danshensu (DSS), salvianolic acid B (SAB), cryptotanshinone (CTS), tanshinone II A (TS II A), and total tanshinone (TTS) are the main bioactive components in extracts of $S$. miltiorrhizae roots [24-26]. We therefore used these as standards for the HPLC analysis of our plant samples.

\section{Materials and Methods}

\subsection{Field Experiment}

The field experiment was carried out in a field at the
Institute of Medicinal Plant Development (IMPLAD), Chinese Academy of Medical Sciences (CCAMS) and Peking Union Medical College. The soil type is a calcareous alluvial fluvo-aquic soil with a loamy and silty texture (FAO) that is typical of the region. The soil was analyzed before planting. The chemical properties of the $0-40 \mathrm{~cm}$ soil layer were as follows: extracted mineral, $\mathrm{N} 70 \mathrm{~kg} \mathrm{ha}^{-1}$; $\mathrm{pH}\left(\mathrm{H}_{2} \mathrm{O}\right), 7.6-8.0$; soil density, $1.40 \mathrm{~g} \mathrm{~cm}^{-1}$; available $\mathrm{P}, 18.5 \mathrm{mg} \mathrm{kg}^{-1}$; $\mathrm{NH}_{4}$ Ac-extracted $\mathrm{K}, 157.5 \mathrm{mg} \mathrm{kg}^{-1}$; and organic matter, $20 \mathrm{~g}$ $\mathrm{kg}^{-1}$. The field was irrigated with a sprinkler a few days before planting and was ploughed just before planting. The water capacity of the soil was maintained at $60 \%(\mathrm{w} / \mathrm{w})$ after planting. Danshen (S. miltiorrhiza) germplasm lines were planted on $28^{\text {th }}$ April 2015 using conventional commercial cultivation methods. Danshen was thinned at the seedling stage to a density of 55000 plants $\cdot \mathrm{ha}^{-1}$. Urea was added as a fertilizer at a rate of $150 \mathrm{~kg} \mathrm{ha}^{-1} \mathrm{~N}$. We applied $30 \%$ of the urea fertilizer before planting and the rest as a topdressing after the seedlings reached $15 \mathrm{~cm}$ in height. Additionally, $52 \mathrm{~kg} \mathrm{ha}^{-1} \mathrm{P}$ (superphosphate) and $55 \mathrm{~kg} \mathrm{ha}^{-1} \mathrm{~K}$ (potassium chloride) were banded. The experiment had 4 replicates, each with 230 plants. The distance between rows and plants in rows was $0.55 \mathrm{~m}$ and $0.33 \mathrm{~m}$, respectively. Border plots were included, and weed growth on plots was controlled using hand planters.

$S$. miltiorrhizae was harvested on $25^{\text {th }}$ September, $22^{\text {nd }}$ October, and $22^{\text {nd }}$ November, 2015. Twenty plants were harvested randomly at each growth stage. We used the same planting time, cultivation methods, and harvest dates in 2016. Precipitation and air temperature during the growing season in 2015 and 2016 are shown in Figure 1, and the water capacity of field soil was maintained about $80 \%(w / w)$ with little irrigation.

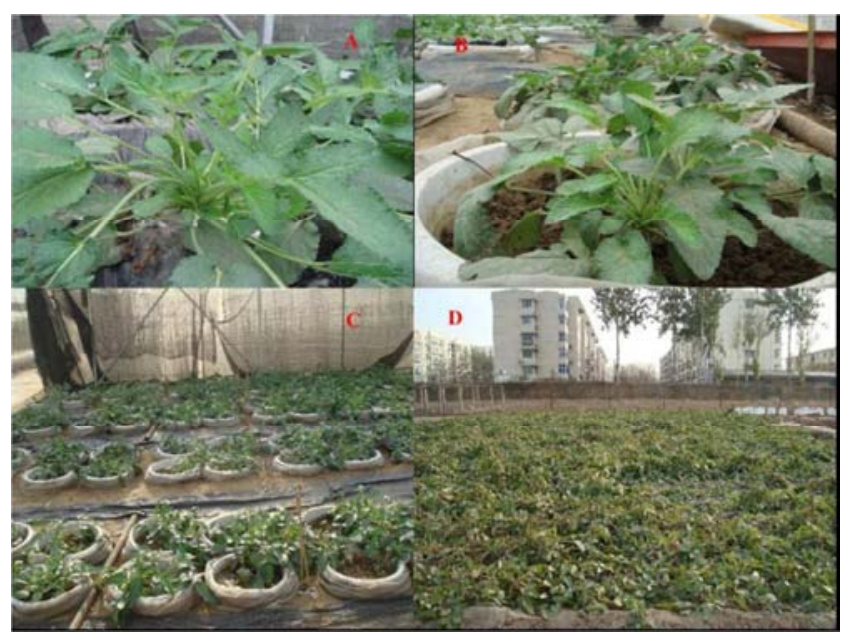

Figure 1. Radix Salvia miltiorrhiza (Fam. Labiatae) in quartz sand-pot, soil-pot and outside field cultures (photo credits: $X$. L. Zhang). $A=$ quartz-sand-pot culture (hydroponics culture), $B=$ soil-pot culture, $C=$ quartz sand-pot and soil-pot cultures in greenhouse, $D=$ outside field culture.

\subsection{Greenhouse Experiments}

S. miltiorrhizae germplasm lines were planted in a field at IMPLAD, CAMS, Beijing, China using conventional cultivation methods on $28^{\text {th }}$ April 2015 and $28^{\text {th }}$ April 2016.S. 
miltiorrhizae seedlings at the 4-leaf stage were transplanted into each pot used in greenhouse experiments.

S. miltiorrhizae was harvested at different growth stages, on $30^{\text {th }}$ September, $30^{\text {th }}$ October, and $30^{\text {th }}$ November, 2015, and on the same dates in 2016. Ten pots were harvested at each growth stage in the quartz-sand-pot and soil-pot experiments. The greenhouse temperatures are shown in Figure. 2.

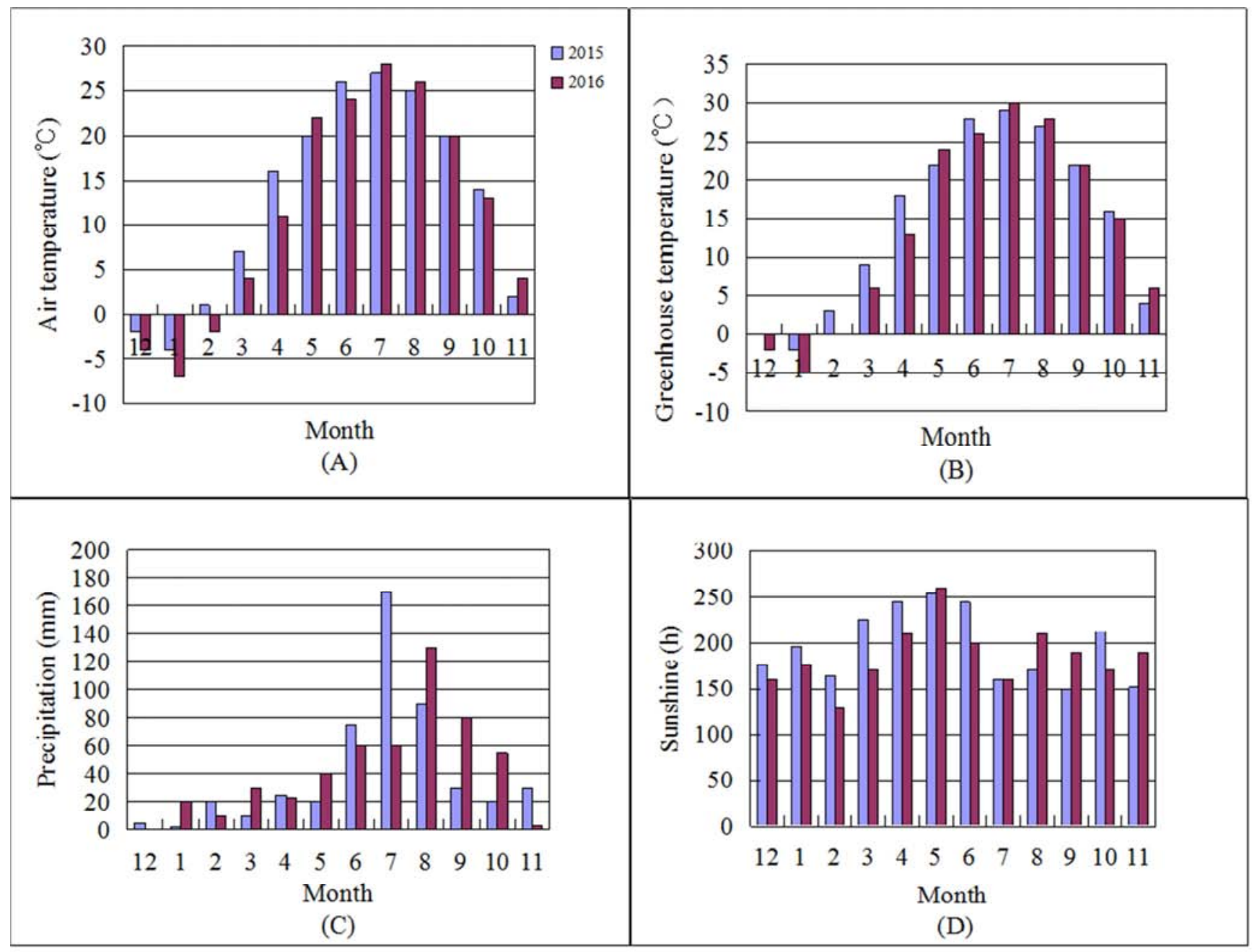

Figure 2. Temperature in the greenhouse (A), outside field (B), precipitation (C), and incident sunlight (D) in Beijing, China in 2015 and 2016.

\subsubsection{Quartz Sand-Pot Experiment}

S. miltiorrhizae seedlings were transplanted into 30 plastic pots ( $25 \mathrm{~cm}$ diameter and $40 \mathrm{~cm}$ height), each pot had $30 \mathrm{~kg}$ of quartz sand $(0.25-0.5 \mathrm{~mm}$ diameter), and a total of $900 \mathrm{~kg}$ quartz sand was used in this experiment. Plants were watered with nutrient solution every other day for 10 days during the seedling stage, as described by Hoagland and Arnon (1950) [27]. The $\mathrm{pH}$ of the nutrient solution was adjusted to 6.0. nutrients were in excess of plant requirements containing $3 \mathrm{~g}$ $\mathrm{N}, 0.8 \mathrm{~g} \mathrm{P}, 2.5 \mathrm{~g} \mathrm{~K}$ per plant, the total amounts of each nutrient were supplied to the plants during the entire growth period. Small holes in the bottom of the pots allowed drainage. Evaporation from the pots was minimized by covering the exposed surface of the quartz sand with a layer of black plastic film. White filter paper was placed over the plastic film in order to avoid temperature increases due to incident sunlight. The plants were grown in a greenhouse at IMPLAD, CAMS, Beijing. The water capacity of sand in the pots was maintained at $60-80 \%(\mathrm{w} / \mathrm{w})$ during the experiment.

\subsubsection{Soil-Pot Experiment}

We filled 30 plastic pots ( $25 \mathrm{~cm}$ diameter and $40 \mathrm{~cm}$ height) with a mixture of soils ( $30 \mathrm{~kg}$ soil in each pot, for a total of 900 $\mathrm{kg}$ soil in the experiment). The soils included basic fertilizers (the fertilizers which were applied and mixed with soils before transplanting the seedlings) and low-nutrient river sand-soil. In the river-washing sand-soil, the soil to sand ratio was $3: 1$ $(\mathrm{v} / \mathrm{v})$. The sand-soil was passed through a $0.5-\mathrm{cm}$-mesh sieve prior to placement in the pots. The chemical properties of the original sand-soil were as follows: organic matter content $=$ $10.16 \mathrm{~g} \cdot \mathrm{kg}^{-1}$, available $\mathrm{N}=26.35 \mathrm{mg} \cdot \mathrm{kg}^{-1}$, available $\mathrm{P}=12.85$ $\mathrm{mg} \cdot \mathrm{kg}^{-1}$, and available $\mathrm{K}=65.20 \mathrm{mg} \cdot \mathrm{kg}^{-1}$. Pots were placed in a flat membrane greenhouse (Figure. 1). Plants were kept under a rain shelter with sufficient sunlight. The soil in the pots was maintained at a water capacity of $80 \%(\mathrm{w} / \mathrm{w})$ during the experiment. 


\subsection{Plant Measurements and Active Component Analysis}

\subsubsection{Plant Measurements}

Representative examples of experimental sites and $S$. miltiorrhizae plants harvested from field, quartz sand-pot and soil-pot culture experiments are shown in Figure. 1. Shoots (leaves and stems) and roots were separated and the longest root length (LRL), largest root diameter (LRD), number of roots (RN), shoot dry weight (SDW), root dry weight (RDW), and total plant dry weight (PDW) were recorded. Shoots and roots were dried at $60^{\circ} \mathrm{C}$ for $72 \mathrm{~h}$ prior to weighing. Shoots and roots were then ground until they were able to pass through a 0.3 -mm sieve.

\subsubsection{Chemicals and Standards}

HPLC grade acetonitrile and methanol were purchased from Fisher Scientific (NJ, USA). Deionised water was purified using the Milli-Q system (Millipore, Bedford, MA, USA). Analytical grade phosphoric acid and ethanol were purchased from Beijing BeiHua Fine Chemicals Co. Ltd. (Beijing, China). Authentic standards of danshensu, salvianolic acid B, tanshinone IIA and cryptotanshinone were purchased from the National Institute for Control of Biological and Pharmaceutical Products (Beijing, China).

\subsubsection{HPLC Analysis}

CTS, TSIIA, DSS, and SAB were measured using HPLC. The analysis method referenced Lu et al. (2015) [28].

\subsubsection{UV Spectrophotometry}

TTS was analyzed using UV spectrophotometry. Individual samples $(0.500 \mathrm{~g})$ were accurately weighed and soaked in $5 \mathrm{ml}$ ethanol at $4^{\circ} \mathrm{C}$ overnight. Samples were then extracted in an ultrasonic bath at room temperature for $20 \mathrm{~min}$. After centrifugation at $2856 \times g$ for $20 \mathrm{~min}, 0.5 \mathrm{ml}$ of the resulting supernatant was diluted with $3.5 \mathrm{ml}$ ethanol and analyzed using an ultraviolet spectrophotometer (UV1100-vis;
Shanghai Tianmei Instrument Co., Ltd., Shanghai, China) at a detection wave length of $270 \mathrm{~nm}$.

\subsubsection{Inductive Coupled Plasma (ICP) Analysis}

Concentrations of $\mathrm{P}$ and $\mathrm{K}$ in plant parts were determined using inductively couple plasma (ICP) emission spectroscopy (ICPE-9000; Japan, Tsujima). N was determined using an automatic Kjeltec Distilling system (Kjeltec 8400; Germany). Approximately $0.2 \mathrm{~g}$ dried and ground samples were ashed in a muffle furnace at $600^{\circ} \mathrm{C}$ for $4 \mathrm{~h}$. The ash was digested by adding $1.0 \mathrm{~mL} 6 \mathrm{M} \mathrm{HCl}$ for $1 \mathrm{~h}$ and in $40 \mathrm{~mL}$ of a double-acid solution containing $0.0125 \mathrm{M} \mathrm{H}_{2} \mathrm{SO}_{4}$ and $0.05 \mathrm{M} \mathrm{HCl}$ for an additional $1 \mathrm{~h}$. the digested solution was then filtered using $2 \mathrm{~V}$ Whatman filter paper (Shanghai, China) and analysed for N, P and $\mathrm{K}$.

\subsection{Statistical Analysis}

Treatment effects were determined by one-way analysis of variance (ANOVA). Differences between treatments were confirmed using least significant difference tests (LSDTs). SPSS 13.0 software was used for all statistical analyses (SPSS Inc, USA).

\section{Results}

\subsection{N, P, and K element Concentration in Plant Tissue}

Although S. miltiorrhiza was supplied with the same amount of nutrients in all 3 culture systems, the $\mathrm{N}, \mathrm{P}$, and $\mathrm{K}$ concentrations in plants (root and shoot) grown in quartz sand-pots (hydroponic culture system) were all lower than the concentrations in plants grown in soil-pot and field systems. Plants grown using the hydroponic culture system had significantly less $\mathrm{N}$ than plants grown using soil-pot and field systems $(p<0.05$; Figure. 3).

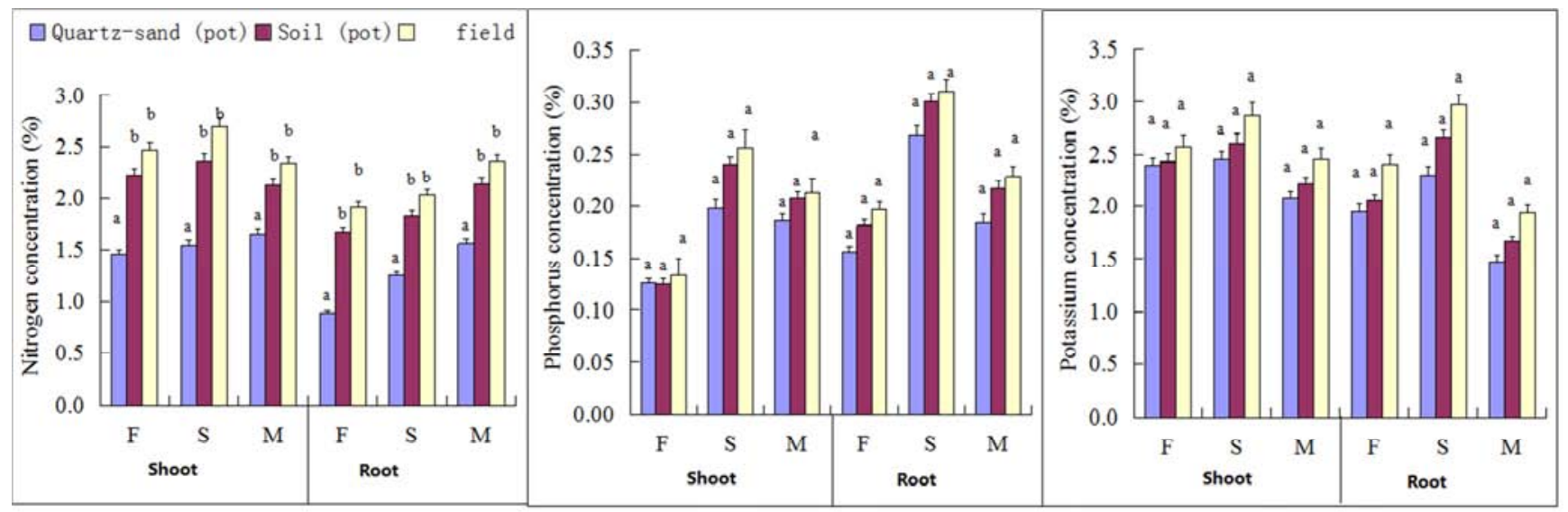

Figure 3. Nitrogen, phosphorus and potassium concentrations in shoots and roots of S. miltiorrhiza at 3 growth stages, flowering (F), root swelling (S), and mature (M), grown in quartz sand-pot (blue bars), soil-pot (red bars), and outside-field cultures (yellow bars). Values are means ( \pm SE; $n=20)$. For each metabolite, different letters within cultures indicate significant differences, as determined by the least significant difference test (LSDT). 


\subsection{The Effect of Culture System on Root Growth and Bioactive Components of Roots at Different Growth Stages}

\subsubsection{Plant Growth}

The LRL, LRD, SDW, RDW, and PDW of plants grown in an outside field system were higher than those of plants grown using hydroponic culture and soil-pot systems (Table 1). Compared with plants grown using a hydroponic culture system, plants grown in the outside field system had average LRL, LRD, RN, SDW, RDW, and PDW that were $57 \%, 46 \%$, $48 \%, 185 \%, 164 \%$, and $178 \%$ greater at the flowering stage, respectively. Compared with the soil-pot system, plants grown in the outside field system had LRL, LRD, SDW,
RDW, and PDW that were $14 \%, 12 \%, 60 \%, 44 \%$, and $54 \%$ greater at the flowering stage, respectively. At the root swelling stage, plants grown in the field system had LRL, LRD, RN, SDW, RDW, and PDW that were $48 \%, 46 \%, 65 \%$, $210 \%, 112 \%$, and $154 \%$ greater than those of plants grown using a hydroponic system, respectively. Compared with plants grown in the soil-pot system, these values were $9 \%$, $16 \%, 15 \%, 94 \%, 68 \%$, and $83 \%$ greater, respectively. At the flowering and root swelling stages, the LRL, LRD, and RN of plants grown using the hydroponic culture system were significantly lower than those of plants grown in the field and soil-pot systems $(p<0.01)$. SDW, RDW, and PDW differed significantly between all 3 culture systems $(p<0.01)$.

Table 1. Root parameters and dry biomass of Salvia miltiorrhiza plants grown in quartz-sand-pot, soil-pot and outside field cultures at 3 different growth stages.

\begin{tabular}{|c|c|c|c|c|c|}
\hline \multirow{2}{*}{ Stages } & \multirow{2}{*}{ Growth parameters } & & \multicolumn{3}{|c|}{ Cultivation systems } \\
\hline & & & Quartz Sand-pot & Soil-pot & Field \\
\hline \multirow{7}{*}{$\mathrm{F}^{1}$} & The longest root length $(\mathrm{cm})$ & & ${ }^{2} 18.36 \pm 0.82 \mathrm{aA}$ & $25.16 \pm 1.00 \mathrm{bB}$ & $28.76 \pm 1.06 \mathrm{bB}$ \\
\hline & The largest root diameter $(\mathrm{mm})$ & & $5.17 \pm 0.20 \mathrm{aA}$ & $6.72 \pm 0.31 \mathrm{bB}$ & $7.54 \pm 0.34 \mathrm{bB}$ \\
\hline & The number of roots (n) & & $4.25 \pm 0.18 \mathrm{aA}$ & $6.85 \pm 0.26 \mathrm{bB}$ & $6.30 \pm 0.30 \mathrm{bB}$ \\
\hline & \multirow{3}{*}{ Biomass dry matter $\left(\mathrm{g} \cdot\right.$ plant $\left.^{-1}\right)$} & Shoot & $4.39 \pm 0.19 \mathrm{aA}$ & $7.83 \pm 0.30 \mathrm{bB}$ & $12.52 \pm 0.61 \mathrm{cC}$ \\
\hline & & Root & $2.23 \pm 0.09 \mathrm{aA}$ & $4.08 \pm 0.15 \mathrm{bB}$ & $5.88 \pm 0.29 \mathrm{cC}$ \\
\hline & & Total plant & $6.61 \pm 0.29 \mathrm{aA}$ & $11.91 \pm 0.45 \mathrm{bB}$ & $18.39 \pm 0.91 \mathrm{cC}$ \\
\hline & Root/Shoot & & $0.53 \pm 0.02 \mathrm{aA}$ & $0.52 \pm 0.02 \mathrm{aA}$ & $0.47 \pm 0.02 \mathrm{aA}$ \\
\hline \multirow{7}{*}{$S^{1}$} & The longest root length $(\mathrm{cm})$ & & $28.82 \pm 1.21 \mathrm{aA}$ & $39.27 \pm 1.50 \mathrm{bB}$ & $42.66 \pm 1.82 \mathrm{bB}$ \\
\hline & The largest root diameter $(\mathrm{mm})$ & & $6.66 \pm 0.28 \mathrm{aA}$ & $8.40 \pm 0.36 \mathrm{bB}$ & $9.73 \pm 0.43 \mathrm{bB}$ \\
\hline & The number of roots (n) & & $5.14 \pm 0.22 \mathrm{aA}$ & $7.38 \pm 0.34 \mathrm{bB}$ & $8.49 \pm 0.30 \mathrm{bB}$ \\
\hline & \multirow{3}{*}{ Biomass dry matter $\left(\mathrm{g} \cdot \mathrm{plant}^{-1}\right)$} & Shoot & $8.02 \pm 0.34 \mathrm{aA}$ & $12.83 \pm 0.49 \mathrm{bB}$ & $24.89 \pm 1.15 \mathrm{cC}$ \\
\hline & & Root & $6.94 \pm 0.30 \mathrm{aA}$ & $8.77 \pm 0.34 \mathrm{bB}$ & $14.72 \pm 0.65 \mathrm{cC}$ \\
\hline & & Total plant & $15.60 \pm 0.70 \mathrm{aA}$ & $21.60 \pm 0.83 \mathrm{bB}$ & $39.60 \pm 1.96 \mathrm{cC}$ \\
\hline & Root/Shoot & & $0.87 \pm 0.04 \mathrm{aA}$ & $0.69 \pm 0.03 \mathrm{bA}$ & $0.60 \pm 0.03 \mathrm{bA}$ \\
\hline \multirow{7}{*}{$\mathrm{M}^{1}$} & The longest root length $(\mathrm{cm})$ & & $37.59 \pm 1.56 \mathrm{aA}$ & $42.86 \pm 1.70 \mathrm{bB}$ & $46.72 \pm 2.12 \mathrm{bB}$ \\
\hline & The largest root diameter $(\mathrm{mm})$ & & $7.89 \pm 0.34 \mathrm{aA}$ & $9.90 \pm 0.39 \mathrm{bB}$ & $12.18 \pm 0.63 \mathrm{cC}$ \\
\hline & The number of roots (n) & & $6.22 \pm 0.27 \mathrm{aA}$ & $8.58 \pm 0.34 \mathrm{bB}$ & $10.06 \pm 0.41 \mathrm{cC}$ \\
\hline & \multirow{3}{*}{ Biomass dry matter $\left(\mathrm{g} \cdot\right.$ plant $\left.^{-1}\right)$} & Shoot & $6.56 \pm 0.26 \mathrm{aA}$ & $9.21 \pm 0.37 \mathrm{bB}$ & $18.91 \pm 0.86 \mathrm{cC}$ \\
\hline & & Root & $8.20 \pm 0.33 \mathrm{aA}$ & $11.27 \pm 0.37 \mathrm{bB}$ & $19.57 \pm 0.86 \mathrm{cC}$ \\
\hline & & Total plant & $14.76 \pm 0.59 \mathrm{aA}$ & $20.48 \pm 0.79 \mathrm{bB}$ & $38.48 \pm 1.74 \mathrm{cC}$ \\
\hline & Root/Shoot & & $1.25 \pm 0.05 \mathrm{aA}$ & $1.23 \pm 0.05 \mathrm{aA}$ & $1.04 \pm 0.15 \mathrm{aA}$ \\
\hline
\end{tabular}

$\mathrm{F}=$ plants in flowering stage, $\mathrm{S}=$ plants in root swelling stage, $\mathrm{M}=$ plants in maturing stage, ${ }^{1}$ the average results from culture experiments conducted in 2015 and $2016,{ }^{2}$ mean values $( \pm \mathrm{SE} ; \mathrm{n}=20)$. For root parameters and biomass, distinct letters within columns indicate different significant values, lowercase for $5 \%$ and uppercase for $1 \%$.

At the mature stage, plants grown in a field system had LRL, LRD, RN, SDW, RDW, and PDW that were $24 \%, 54 \%, 62 \%$, $188 \%, 139 \%$, and $161 \%$ greater than those grown using the hydroponic culture system, respectively. These plants had LRL, LRD, RN, SDW, RDW, and PDW that were 9\%, 23\%, $17 \%, 105 \%, 74 \%$, and $88 \%$ greater than those grown in a soil-pot system, respectively. At the mature stage, the LRL of plants grown using a hydroponic culture system were significantly lower than those of plants grown in field and soil-pot systems $(p<0.01)$. There was a significant difference in LRD, RN, SDW, RDW, and PDW between the 3 culture systems $(p<0.01$ for all except for differences between field and soil-pot LRD and RN, for which $p<0.05$ ).

In all 3 culture systems, the ratio of root to shoot $(\mathrm{R} / \mathrm{S})$ increased gradually as the $S$. miltiorrhiza grew. The $\mathrm{R} / \mathrm{S}$ ratio of plants grown in the hydroponic culture system showed the greatest increase, followed by that of plants grown in the soil-pot system. At the root swelling stage, the R/S ratio of plants grown in the hydroponic culture system was significantly higher than those of plants grown in soil-pot and field systems $(p<0.05)$ (Table 1$)$. 


\subsubsection{Bioactive Components}
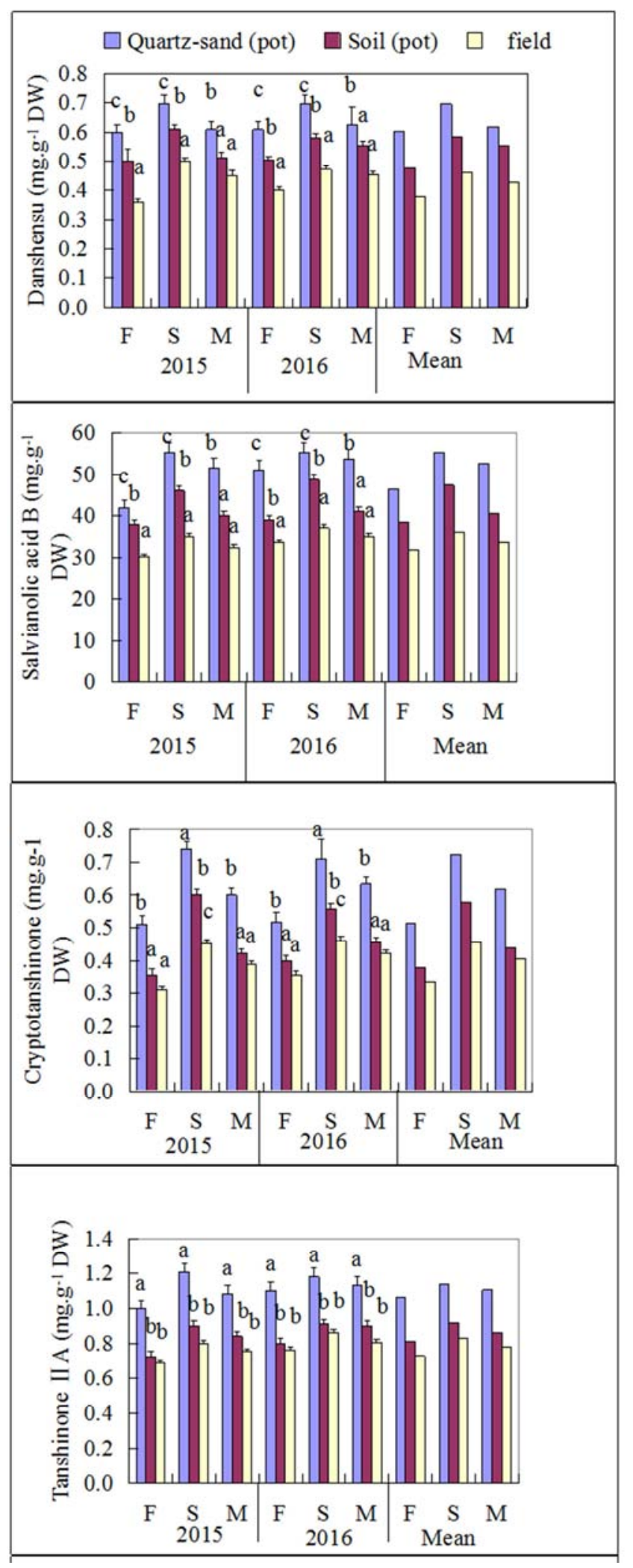

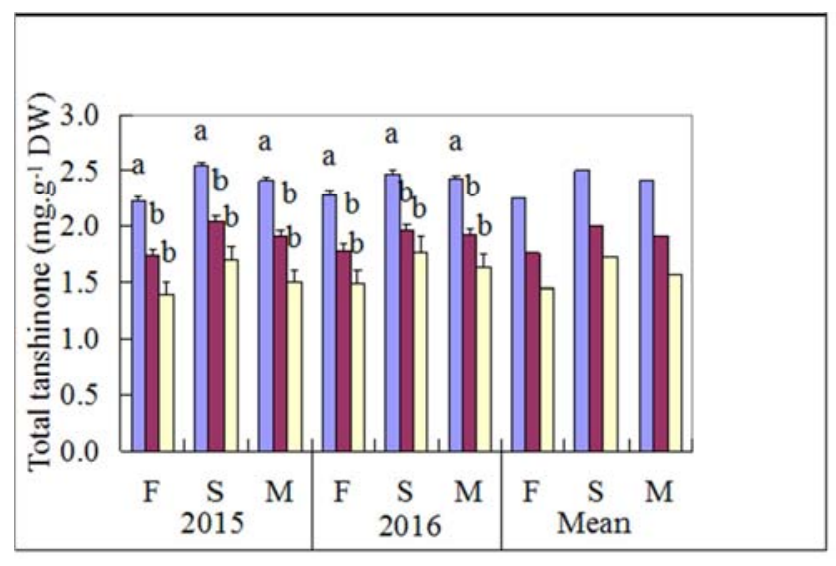

Figure 4. Concentration of 5 bioactive compounds in the roots of $S$. miltiorrhiza at 3 growth stages, flowering $(F)$, root swelling $(S)$, and mature (M), grown in quartz sand-pot (blue bars), soil-pot (red bars), and outside-field cultures (yellow bars). Values are means $( \pm S E ; n=20)$. For each metabolite, different letters within the cultures indicate significant differences, as determined by least significant difference test (LSDT).

The changes between growth stages in the concentration of 5 active constituents of $S$. miltiorrhiza are shown in Figure 4. S. miltiorrhiza contained more SAB than any other bioactive compound tested. At every growth stage, plants grown in the hydroponic culture system had higher concentrations of all 5 bioactive compounds than plants grown in soil-pot and field systems. In the flowering and root swelling stages, DSS and $\mathrm{SAB}$ content differed significantly between the 3 culture systems $(p<0.05)$. At the mature stage, plants grown in the hydroponic culture system had a significantly higher SAB content than plants grown in the soil-pot and field systems ( $p$ $<0.05)$, There was no significant difference in the bioactive component contents of plants grown in soil-pot and field. The CTS content of plants grown in the hydroponic culture system was significantly higher than those of plants grown in soil-pot and field systems at all 3 growth stages $(p<0.05)$. The CTS content of plants grown in the soil-pot system was higher than that of plants grown in the field system at all 3 growth stages; however, this difference was only significant at the root swelling stage $(p<0.05)$. Throughout the entire growth cycle, plants grown in the hydroponic cultural system had significantly higher TS II A and TTS content than plants grown in the soil-pot and field systems $(p<0.05)$. Plants grown in the soil-pot system and those grown in the field system did not differ significantly in TS II A and TTS content. Within each culture system, the concentrations of bioactive compounds (DSS, SAB, CTS, TS II A, and TTS) were highest at the root swelling stage, and lowest at the flowering stage. The bioactive compound content of plants was significantly lower at the flowering stage than at the root swelling and mature stages.

\subsection{Yield of Bioactive Components}

The bioactive component yield was determined by multiplying the root concentration by root dry weight (Figure 5). At all 3 growth stages, the yield of the 5 bioactive components from plants grown in the field system 
were the highest (average dry weight DSS, $8.36 \mathrm{mg} \cdot$ plant $^{-1}$; $\mathrm{SAB}, 657 \mathrm{mg} \cdot \mathrm{plant}^{-1}$; CTS, $7.95 \mathrm{mg} \cdot \mathrm{plant}^{-1}$; TS II A, 15.2 $\mathrm{mg} \cdot$ plant $^{-1}$; and TTS, $30.7 \mathrm{mg} \cdot$ plant $^{-1}$, at the mature stage), followed by the yield from plants grown in the soil-pot system (DSS, $6.25 \mathrm{mg} \cdot$ plant $^{-1}$; SAB, $457 \mathrm{mg} \cdot$ plant $^{-1}$; CTS, $5.06 \mathrm{mg} \cdot$ plant $^{-1}$; TS II A, $9.7 \mathrm{mg} \cdot$ plant $^{-1}$; and TTS, 21.6 $\mathrm{mg} \cdot$ plant $^{-1}$, at the mature stage), then by the yield from plants grown in the hydroponic culture system (DSS, 5.07 $\mathrm{mg} \cdot$ plant $^{-1}$; SAB, $430 \mathrm{mg} \cdot$ plant $^{-1}$; CTS, $4.95 \mathrm{mg} \cdot$ plant $^{-1}$; TS II A, $9.1 \mathrm{mg} \cdot$ plant $^{-1}$; and TTS, $19.8 \mathrm{mg} \cdot$ plant $^{-1}$, at the mature stage). In comparison to the yield from plants grown in the soil-pot and hydroponic systems, plants grown in the field system had a DSS yield that was $14 \%$ and $66 \%$ greater, an SAB yield that was $19 \%$ and $81 \%$ greater, a CTS yield that was $27 \%$ and $71 \%$ greater, a TS II A that was $29 \%$ and $80 \%$ greater, and a TTS yield that was $18 \%$ and $69 \%$ greater at the flowering stage, respectively. In comparison to the yield from plants grown in the soil-pot and hydroponic systems, plants grown in the field system had a DSS yield that was $32 \%$ and $40 \%$ greater, an SAB yield that was $28 \%$ and $38 \%$ greater, a CTS yield that was $33 \%$ and $34 \%$ greater, a TS II A yield that was $52 \%$ and $55 \%$ greater, and a TTS yield that was $45 \%$ and $46 \%$ greater at the root swelling stage, respectively. In comparison to the yield from plants grown in the soil-pot and hydroponic systems, plants grown in the field system had a DSS yield that was $34 \%$ and $65 \%$ greater, an SAB yield that was $44 \%$ and $53 \%$ greater, a CTS yield that was $60 \%$ and $57 \%$ greater, a TS II A yield that was $56 \%$ and $68 \%$ greater, and a TTS yield that was $42 \%$ and $55 \%$ greater at the mature stage, respectively. In each culture system, the yield of all 5 bioactive components was greatest at the mature stage, followed at the root swelling stage, and was lowest at the flowering stage. The yield of all 5 bioactive components from plants collected at the root swelling and mature stages from the 3 systems were significantly greater than those from plants collected at the flowering stage $(p<0.01)$. However, the differences between the yields from plants collected at the root swelling stage and those collected at the mature stage were not significantly different.

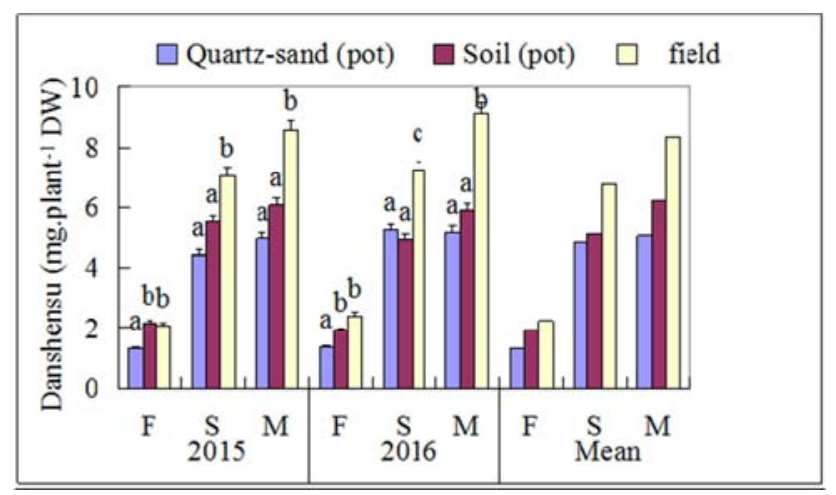

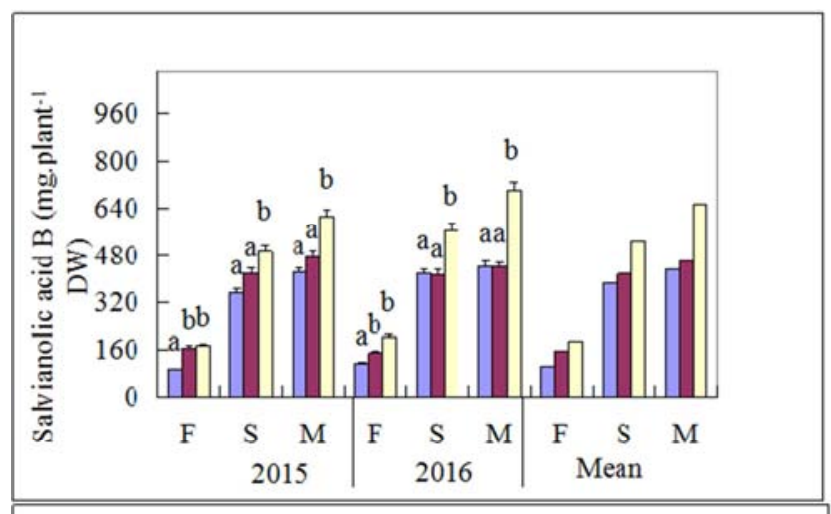
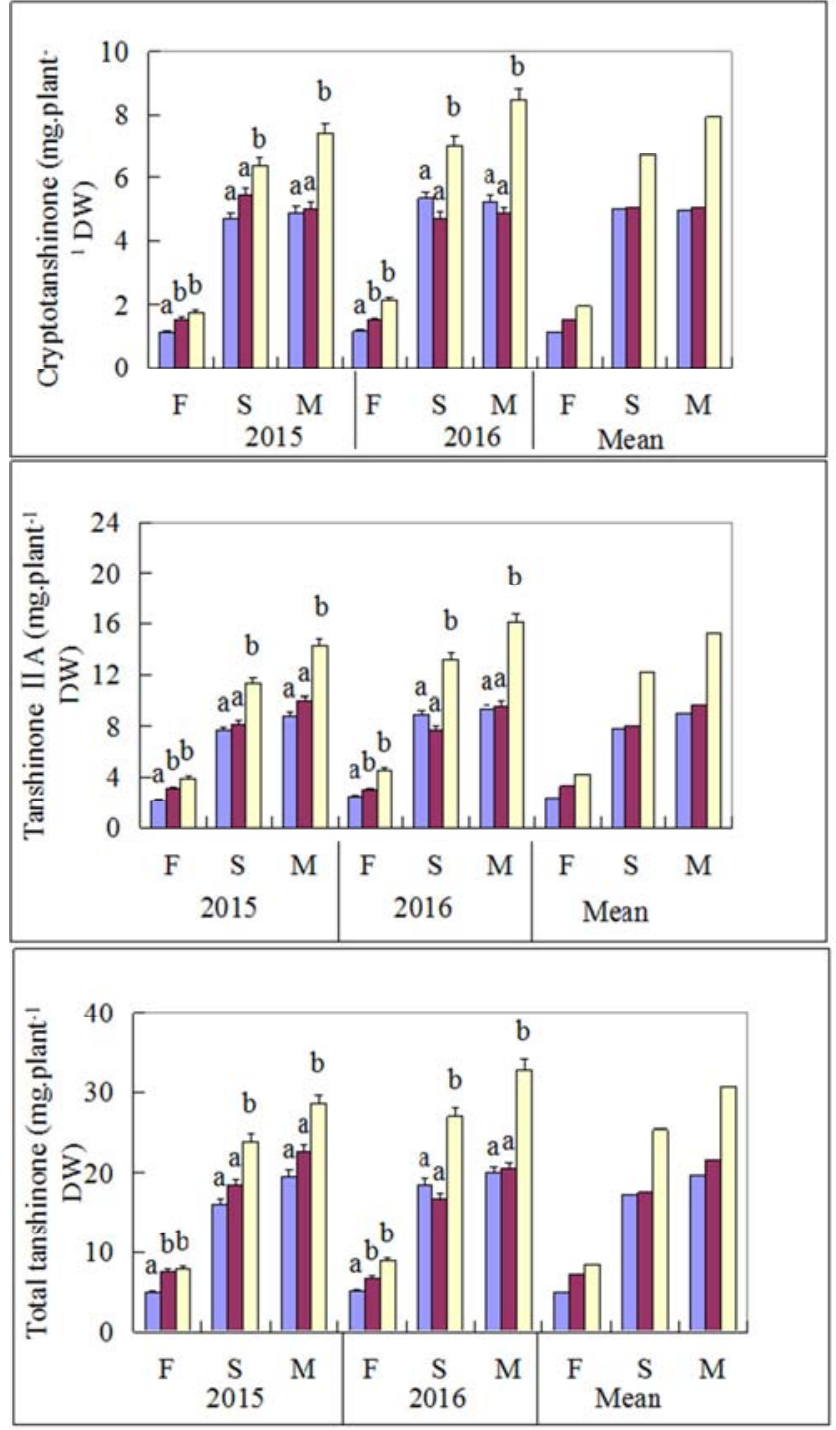

Figure 5. Yield of 5 bioactive compounds in roots of S. miltiorrhiza at 3 growth stages, flowering $(F)$, root swelling $(S)$, and mature $(M)$, grown in quartz sand-pot (blue bars), soil-pot (red bars), and outside-field cultures (yellow bars). Values are means $( \pm S E ; n=20)$. For each metabolite, different letters within cultures indicate significant differences as determined by least significant difference test (LSDT). 


\section{Discussion}

The medically active compounds in S. miltiorrhiza, and medicinal plants in general, are produced by plant secondary metabolism in response to environmental stress [29-31]. The production of high-quality medicinal plant tissues requires the optimization of growing environments for consistent production of specific metabolites. However, information about the effect of culture methods on plant growth and phytochemical yield is limited. The main objective of the current study was to evaluate 3 culture systems in controlled and outside environments in order to optimize phytochemical production in plant biomass, phenolic and tanshione concentrations, and active component yield were considered. The experimental results from 2015 and 2016 differed somewhat in root parameters (including RDW, LRL, and LRD) and bioactive concentration; these differences were not statistically significant. The results from both years showed the same trends, and any differences in results may be due to slight differences in climactic conditions between years.

Table 2. Approximate concentration range of 5 bioactive components in the roots of Salvia miltiorrhiza from 3 culture experiments, and spontaneous collection, and previous field cultivation.

\begin{tabular}{|c|c|c|c|c|c|}
\hline Growing systems & DSS (mg g $\left.{ }^{-1} \mathrm{DW}\right)$ & SAB (mg g ${ }^{-1}$ DW) & CTS (mg g gW) & TS II A (mg g $\left.{ }^{-1} \mathrm{DW}\right)$ & TTS (mg g ${ }^{-1}$ DW) \\
\hline Quartz sand-pot ${ }^{\mathrm{a}}$ (hydroponics) & $0.4-0.6$ & $30-40$ & $0.40-0.6$ & $0.5-0.7$ & $1.2-1.6$ \\
\hline Soil-pot ${ }^{\mathrm{a}}$ & $0.6-0.8$ & $38-50$ & $0.5-0.7$ & $1-1.2$ & $2-2.4$ \\
\hline Field $^{\mathrm{a}}$ & $0.6-1.1$ & $40-65$ & $0.5-0.8$ & $1-2.1$ & $2.2-2.6$ \\
\hline $\begin{array}{l}\text { Spontaneous collection or } \\
\text { previous field cultivation }\end{array}$ & $\begin{array}{l}0.24-0.48^{\mathrm{b}} \\
0.34-3.56^{\mathrm{c} 1} \\
0.37-3.03^{\mathrm{c} 2}\end{array}$ & $\begin{array}{l}13.5-22^{\mathrm{b}} \\
11-52^{\mathrm{c} 1} \\
21-41^{\mathrm{c} 2}\end{array}$ & $\begin{array}{l}0.06-1.84^{\mathrm{b}}, 0.57- \\
4.55^{\mathrm{c} 1} \\
0.40-2.40^{\mathrm{c} 1}\end{array}$ & $\begin{array}{l}0.14-6.67^{\mathrm{b}} \\
0.705-8.357^{\mathrm{c} 1} \\
0.799-7.371^{\mathrm{c} 2}\end{array}$ & $0.83-11.2^{\mathrm{b}}$ \\
\hline
\end{tabular}

${ }^{a}$ results from current experiment $(\mathrm{n}=20$ each condition $) ;{ }^{\mathrm{b}} \mathrm{Li}$ et al. $(2008 ; \mathrm{n}=30)$; ${ }^{\mathrm{c}} \mathrm{Ma}$ et al. $\left(2004 ; \mathrm{n}_{\mathrm{c} 1}=23 ; \mathrm{n}_{\mathrm{c} 2}=7\right)[14,39]$.

Because plants grown in each culture system were provided with the same amount of nutrients, the observed difference in plant nutrient absorption between culture systems is probably due to some other aspect of the culture systems. The results related to the bioactive components implies that $S$. miltiorrhiza is capable of bioactive compound biosynthesis and accumulation at low nutrient concentrations. Nutrient levels not only determine plant growth, but also the amount of secondary metabolites in plant tissues, as nutritional deficiency greatly stimulates the production of secondary metabolites [32-33]. Our results are consistent with studies that indicate low N, P, and K supply significantly increase secondary metabolites in medicinal plant tissues [34-36]. Under low nutrient conditions, plants may intensify metabolic and biochemical activity in order to increase the absorptive capacity of roots. This results in an increase in the production of secondary metabolites. However, in the current study, the field system resulted in the greatest root production and the highest yield of bioactive components, followed by the soil-pot system, and then by the hydroponic culture system. In the field system, plant roots always had sufficient water, nutrients, dissolved oxygen (as measured during the experiment, data not shown) and a large elongation space. These conditions may have been more favourable to plant growth than conditions in the other 2 culture systems tested.

The yield of bioactive compounds was significantly greater in the field system than in the hydroponic culture and soil-pot systems, but this difference was highly dependent on the difference in root biomass between culture systems. Zhu et al. (2009) found a similar relationship between growth and saikosaponin production in the medicinal herb Bupleurum chinense DC [30]. Throughout the literature, the reports indicate that significant increases in the bioactive compound yield of plants is the result of increases in biomass, not bioactive compound concentration. Therefore, biomass production is more important than bioactive component concentration for maximizing the hectare yield of $S$. miltiorrhiza.

In all 3 growth stages, the $\mathrm{R} / \mathrm{S}$ ratio of plants grown in the hydroponic culture system was the greatest, followed by that of plants grown in the soil-pot system, and then by that of plants grown in the field system. This indicates that plants grown in the hydroponic culture system had significantly reduced growth, compared to plants grown in the other 2 culture systems, according to its lower root biomasses.

The concentration of individual phenolic and tanshinone compounds is reported to be related to the growth stage of plants [37]. In the current study, plant growth parameters and bioactive compounds differed between culture systems at all stages of growth. Plants grown in the field system increased root biomass and decreased the concentration of bioactive components in their roots to a greater degree than plants grown in either the hydroponic culture system or in the soil-pot system. In controlled environments such as hydroponic culture and soil-pot culture systems, the space, water, air, temperature, and nutrients available for plant growth are controlled to a greater degree than is possible in a field system. This control environment influences the ability of plant tissues to grow freely, particularly roots [38].

Compared with plants grown in the soil-pot and field systems, S. miltiorrhiza plants grown in the hydroponic culture system had a higher or similar concentration of medicinal metabolites. This is consistent with previous studies of both cultivated and wild-harvested S. miltiorrhiza plants (Table 2). TS II A and SAB are the markers commonly used for the chemical standardization and quality assessment of $S$. miltiorrhiza roots, even though other bioactive compounds contained in $S$. miltiorrhiza tissues have stronger pharmacological activities (e.g. danshensu and cryptotanshinone) [14]. In hydroponic cultural experiments, most samples contain the minimum concentration of SAB and TSA required to meet quality standards for the production of 
standardized extracts with a final concentration of SAB and TS II A of $30 \mathrm{mg} \cdot \mathrm{g}^{-1}$ and $2 \mathrm{mg} \cdot \mathrm{g}^{-1}$, respectively (CPA, 2010) [41]. In field and soil-pot cultural experiments, the level of TS II A was lower than this minimum concentration (Table 2). However, root biomass is significantly greater in field systems than in hydroponic systems, resulting in a much larger yield of bioactive components than is obtained from hydroponic systems. Our results are not entirely consistent with previous reports of greenhouse hydroponic culture stimulating plant growth, root production, and secondary metabolites in some medicinal plants [15-16, 40-41, 20]. This may result from differences between our study and previous studies on medicinal plant varieties, growing environments, or hydroponic culture substrate and technology.

\section{Conclusion}

The hydroponic culture system facilitated the accumulation of bioactive components in plants, but was not favourable for plant growth and root production. However, the field culture system resulted in significantly greater plant growth and root production than the hydroponic culture system. Further studies are needed in order to develop appropriate growing procedures for large-scale $S$. miltiorrhiza production, and to provide high plant biomass with satisfactory accumulation of bioactive components in the roots of this important medicinal plant.

\section{Acknowledgements}

This research was supported National Natural Science Foundation of China (No. 81403038).

\section{References}

[1] Tan XH, Xue WJ, Ding XM, 2005. Application of Danshen injection on early stage of renal transplantation. Chinese Journal of Integrative Medicine, 25, 404-407.

[2] Wu ZM, Wen T, Tan YF, LiuY, Ren F, Wu H, 2007. Effects of salvianolic acid A on oxidative stress and liver in jury induced by carbon tetrachloride in rats. Basic and Clinical Pharmacology Toxicology, 100, 115-120.

[3] Lam FF, Yeung JH, Cheung JH, Or PM. 2006. Pharmacological evidence for calcium channel inhibition by Danshen (Salvia miltiorrhiza) on rat isolated femoral artery. Journal Cardiovascular Pharmacology, 47, 139-145.

[4] Lin YL, WuC, Luo MH, Huang YJ, Wang CN, Shao MS, Huang YT, 2006. In Vitro protective effects of salvianolic acid B on primary hepatocytes and hepatic stellate cells. Journal of Ethnopharmacology, 105, 215-222.

[5] Sze FK, Yeung FF, Wong E, Lau J, 2005. Does Danshen improve disability after ischaemic stroke? Acta Neurologica Scandinavica, 111, 118-125.

[6] Zhang HS and Wang SQ, 2006. Salvianolic acid B from Salvia miltiorrhiza inhibits tumor necrosis factor- $\alpha$ (TNF- $\alpha$ )-induced MMP-2 up regulation in human aortic smooth muscle cells via suppression of NAD (P) H oxidase-derived reactive oxygen species. Journal of Molecular and Cellular Cardiology, 41,
$138-148$.

[7] Heuberger HB, Bauer F, Friedl G, Heubl J, Hummelsberger R, Nögel R, Seidenberger P, Torres L, 2010. Cultivation and Breeding of Chinese Medicinal Plants in Germany. Planta Medica, 76, 1956-1962.

[8] Xing ZJ and Xing Y, 2009. The analysis about the product and sale of Danshen. Available online: http:// www. bzzyc.cn/Article/Show.asp?ID=8163.

[9] Dorais M, Papadopoulos AP, Luo X, Leonhart S, Gosselin A, Pedneault K, Angers P, Gaudreau L, 2001. Soilless greenhouse production of medicinal plants in North Eastern Canada. Acta Horticulturae: World Congress on Soilless Culture: Agriculture in the Coming Millennium, 554, 297-303.

[10] Mairapetyan S and Manukyan A, 2002. Catmint culture. Practical Hydroponics and Greenhouses, 62, 63-65.

[11] Manukyan A, 2001. The development of biotechnologies of celandine and catmint in outside hydroponics conditions, $\mathrm{PhD}$ diss. summary, 21. National Academy of Sciences of the Republic of Armenia (in Armenian).

[12] Craker L, 2003. Production and demand: A view to the future of MAP, In: Proceedings of the International Conference on Medicinal and Aromatic Plants (Part II), Budapest Hungary 15-21.

[13] Dufault RJ, Rushing J, Hassell T, Shepard BM, McCutcheon G, Ward B, 2003. Influence of fertilizer on growth and marker compound of field-grown Echinacea species and feverfew. Scientia Horticulturae, 98, 61-70.

[14] Li MH, Wei JM, Peng Y, Wu QL, Xiao PG, 2008. Investigation of Danshen and related medicinal plants in China. Journal of Ethnopharmacology, 120, 419-426.

[15] Hassanpouragham MB, Tabatabaie SJ, Nazemiyeh H, Vojodi L, Aazami MA, 2008. Essential oil composition of hydroponically grown Chrysanthemum balsamita L. Journal of Essential Oil-Bearing Plants, 11, 649-654.

[16] Hassanpouragham MB, 2009. Flower heads volatile oil composition of soilless culture grown Chrysanthemum balsamita L. Natural Product Research, 23, 672-677.

[17] Sellami, H. K., Napolitano, A., Masullo, M., Smiti, S., Piacente, S., \& Pizza, C. 2013. Influence of growing conditions on metabolite profile of ammi visnaga, umbels with special reference to bioactive furanochromones and pyranocoumarins. Phytochemistry, 95(6), 197-206.

[18] Treftz, C. 2015. Comparison of nutritional and sensory qualities between hydroponic and soil-grown strawberries and raspberries. Dissertations \& Theses-Gradworks.

[19] Treftz, C., \& Omaye, S. T. 2015. Hydroponic raspberries: determining differences in yield, bioactive compounds, and taste preferences. Journal of the Academy of Nutrition \& Dietetics, 115(9), A42-A42.

[20] Maggini R., Tozzini L, Pacifici S, Raffaelli A, Pardossi A, 2012. Growth and accumulation of caffeic acid derivatives in Echinacea angustifolia DC. Var. angustifolia grown in hydroponics culture. Industrial Crops and Products, 35, 269-273.

[21] Pardossi A, Malorgio F, Incrocci L, Tognoni F, 2005. Hydroponic technologies for greenhouse crops. In: Ramdane, D. (Ed.), Crops: Quality, Growth and Biotechnology. WFL Publisher, Helsinki, pp. 360-378. 
[22] Niu J. F, Peng YF, Li CJ, Zhang FS, 2010. Changes in root length at the reproductive stage of maize plants grown In the field and quartz sand. Journal Plant Nutrition Soil Science, 173, 306-314.

[23] Pedneault K, Léonhart S, Gosselin A, Papadopoulos AP, Dorais M, Angers P, 2000. Variations in concentration of active compounds in four hydroponically- and field-grown medicinal plant species. In: Acta Horticulturae. 580: IV International ISHS Symposium on Artificial Lighting, Plenum Press, New York, pp. 97-175.

[24] Matkowski A, Zielinska S, Oszmianski J, Lamer-Zarawska E, 2008. Antioxidant activity of extracts from leaves and roots of Salvia miltiorrhiza Bunge, S. przewalskii Maxim, and S. verticillata L. Bioresource Technology, 99, 7892-7896.

[25] Dong JE, Liu YB, Liang ZS, Wang WL, 2010. Investigation on ultrasound-assisted extraction of salvianolic acid B from Salvia miltiorrhiza root. Ultrasonics Sonochemistry, 17, 61-65.

[26] Lu YR and Foo LY, 2002. Polyphenolics of Salvia-a review. Phytochemistry, 59, 117-140.

[27] Hoagland DR and Arnon D I, 1950. The water-culture method for growing plants without soil. 2nd edit. Circular. Agricultural Experiment Station, University of California, Berkeley. pp. 32.

[28] Lu LL, Hou S, Zheng TT, Zhang, XL and Wei JH, 2015. Simultaneous determination of five hydrophilic and lipophilic components from roots of salvia miltiorrhiza by hplc. Chinese Herbal Medicines, 7(1), 75-79.

[29] Kirakosyan A, Kaufman P, Warber S, Zick S, Aaronson K, Bolling S, Chang SC, 2004. Applied environmental stresses to enhance the levels of polyphenolics in leaves of hawthorn plants. Physiologia Plantarum, 121, 182-186.

[30] Zhu ZZ, Liang ZS, Han RL, Wang X, 2009. Impact of fertilization on drought response in the medicinal herb Bupleurum chinense DC.: Growth and saikosaponin production. Industrial Crops and Products, 29, 629-633.

[31] Marcus IM, Bolster CH, Cook KL, Opot SR, Walker SL, 2012. Impact of growth conditions on transport behavior of E. coli. Journal of Environmental Monitoring, 14, 984-991.
[32] Chrishaki N and Horiguchi T, 1997. Responses of secondary metabolism in plants to nutrient deficiency. Soil Science Plant Nutrition, 43, 987-91.

[33] Rosa TM, Julkunen TR, Lehto1T, Aphalol PJ, 2001. Secondary metabolites and nutrient concentrations in silver birch seedlings under five levels of daily UV-B exposure and two relative nutrient addition rates. New Phytologist, 150, 121-131.

[34] Gleadow RM and Woodrow IE, 2002. Defense chemistry of cyanogenic Eucalyptus cladocalyx seedlings is affected by water supply. Tree Physiology, 22, 939-986.

[35] Suh E, Park K, Park K, 1999. Effect of different concentrations of nutrient solutions on the growth, yield, and quality of basil. Acta Horticulturae, 502, 56-61.

[36] Udagawa Y, 1995. Some responses of dill (Anethum graveolens) and thyme (Thymus vulgaris), grown in hydroponic, to the concentration of nutrient solution. Acta Horticulturae, 396, 203-210.

[37] He CE, Wei JH, Jin Y, Chen SL, 2010. Bioactive component of the roots of Salvia miltiorrhizae: Changes related to harvest time and germplasms line. Industrial Crops Products, 32, 313-317.

[38] Schlick G, 2000. Nutritional characteristics and biomasses production of Chenopodium quinoa grown in controlled environments. San Jose State University, Master's Theses. Paper, 2112, pp. 1-35.

[39] Manukyan AE, Heuberger HT, Schnitzler WH, 2004. Yield and quality of some herbs of the Lamiaceae family under soilless greenhouse production. Journal of Applied Botany and Food Quality, 78, 193-199.

[40] Mairapetyan SK, 1999. Aromatic plant culture in open-air hydroponics. Acta Horticulturae. II WOCMAP Congress Medicinal and Aromatic Plants, Part 3: Agricultural Production, Post Harvest Techniques, Biotechnology, 503, 33-42.

[41] The Pharmacopoeia Commission of PRC, 2010. Pharmacopoeia of the People's Republic of China Version 2010, vol. 1. Chinese medicine science technology Press, Beijing, pp. 72. 